\title{
The effects of anesthesia types on early postoperative results in elective endovascular repair of aortic aneurysms
}

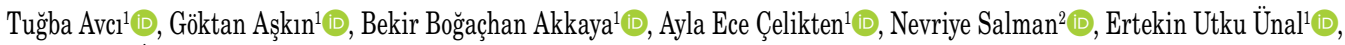 \\ Hakkı Zafer İșcan ${ }^{1}$ D, Șeref Alp Küçüker ${ }^{1} \mathbb{D}$
}

${ }^{1}$ Department of Cardiovascular Surgery, Ankara City Hospital, Ankara, Turkey

${ }^{2}$ Department of Anesthesia and Reanimation, Ankara City Hospital, Ankara, Turkey

\begin{abstract}
Objectives: This study aims to investigate the effects of anesthesia types on early postoperative outcomes in patients treated with endovascular aneurysm repair (EVAR).

Patients and methods: Between January 2012 and January 2018, a total of 134 patients (124 males, 10 females; mean age $69.1 \pm 7.9$ years; range, 52 to 85 years) who were operated under local-locoregional or general anesthesia for abdominal aortic aneurysms were retrospectively analyzed. Type of anesthesia was chosen individually, according to the patient suitability, aneurysm anatomy, and technical difficulty. Early mortality was defined as mortality observed within 30 days after the operation.

Results: Of the patients, 42 were operated under local-locoregional anesthesia and 92 were operated under general anesthesia. There was no conversion to general anesthesia. The mean procedural time was $133.2 \pm 30.4 \mathrm{~min}$ in the local-locoregional group and $156.4 \pm 53.4 \mathrm{~min}$ in the general anesthesia group $(\mathrm{p}=0.012)$. In the early postoperative period, there was one (1.1\%) early mortality. Four patients $(4.3 \%)$ developed renal impairment. One patient $(1.1 \%)$ in the general anesthesia group had myocardial infarction after the procedure. In the local-locoregional group, the mean length of intensive care unit (ICU) stay was $8.5 \pm 6.4 \mathrm{~h}$ and the mean length of hospital stay (LOS) was $2.9 \pm 1.5$ days. In the general anesthesia group, the mean length of ICU stay was $9.6 \pm 0.4 \mathrm{~h}$ and the mean LOS was $3.1 \pm 2.9$ days, indicating a statistically significant difference between the groups in terms of the ICU stay ( $p=0.013)$. The mean amount of radio-opaque solution was also statistically significant between the groups ( $\mathrm{p}=0.01$ ).

Conclusion: Endograft types, the American Society of Anesthesiologists (ASA) classification, patient's emotional health, aneurysm anatomy, and having a high risk for conversion to open surgery are the key factors for choosing the most appropriate anesthesia type. Based on our study results, type of anesthesia does not affect the early results, although local anesthesia is more suitable and most commonly used in unibody grafts and high-risk patients.
\end{abstract}

Keywords: Anesthesia type, endograft type, endovascular aneurysm repair.

Endovascular aneurysm repair (EVAR) of abdominal aortic aneurysms (AAAs) was first defined in the 1990s as a more practical and less destructive alternative to open surgery. ${ }^{[1]}$ With the spread of this technique, the EVAR-1 trial confirmed that 30-day mortality, intensive care unit (ICU) and hospital stay, and blood loss were lower than the open repair. ${ }^{[2]}$ Despite similar long-term results for cardiac events, ${ }^{[3]}$ EVAR has become the first-choice option for AAA repair, owing to its less invasive nature and remarkably better short-term survival rates. ${ }^{[1-2,4,5]}$

After the approval of endovascular repair as a predominant treatment in infrarenal AAAs, the types of anesthesia have recently started to be discussed worldwide. ${ }^{[6-9]}$ In many centers, miscellaneous anesthetic techniques such as general anesthesia, regional anesthesia (including spinal, continuous

Received: April 29, 2019 Accepted: June 28, 2019 Published online: July 19, 2019

Correspondence: Tuğba Avc1, MD. Ankara Şehir Hastanesi Kalp ve Damar Cerrahisi Kliniği, 06800 Çankaya, Ankara, Turkey. e-mail: dr.tugbadonmez@gmail.com 
spinal and epidural anesthesia), and local anesthesia are successfully applied. ${ }^{[10-13]}$

In the present study, we aimed to investigate the effects of anesthesia types on postoperative outcomes in patients treated with elective EVAR.

\section{PATIENTS AND METHODS}

This single-center, retrospective study included a total of 134 patients (124 males, 10 females; mean age $69.1 \pm 7.9$ years; range, 52 to 85 years) who were electively operated under local-locoregional or general anesthesia for AAAs with a modular or unibody endograft in the hybrid operating room by a single surgical team between January 2012 and January 2018. Medical data were retrieved from hospital medical database. All the patients eligible anatomically for elective EVAR treatment were included in the study. Exclusion criteria were as follows: having an urgent intervention, percutaneous simultaneous coronary intervention, or simultaneous coronary artery bypass grafting. A written informed consent was obtained from each patient. The study protocol was approved by the Turkiye Yüksek Ihtisas Training and Research Hospital Ethics Committee. The study was conducted in accordance with the principles of the Declaration of Helsinki.

All symptomatic patients were evaluated by electrocardiogram, echocardiography, and coronary angiography along with pulmonary functional test, chest X-ray, and computed tomography (CT) for anatomic aortic evaluation. Conventional CT and three-dimensional (3D) CT images in which CT data were reformatted in planes perpendicular to the vessel in $3 \mathrm{D}$ space were used to assist in proper endograft selection. During follow-up, conventional CT was performed at one and three months and at six and 12 months according to technical challenge of the procedure individually. We also performed abdominal aortic color Doppler ultrasonography. Early mortality was defined as mortality observed within 30 days after the operation.

\section{Unibody and modular type endograft}

The Endologix AFX device (Endologix Inc., Irvine, CA. USA) consists of a main bifurcated unibody and a proximal aortic extension. This endograft is the only graft with anatomical fixation at the aortic bifurcation. The graft has a 17 French (F) introducer system ipsilaterally and a $9 \mathrm{~F}$ sheath contralaterally. The aortic extension is placed at the infrarenal position. One-side femoral incision and exposure are sufficient and the contralateral side cannulation can be performed percutaneously. Modular endografts consist of the main module with suprarenal fixation and an ipsilateral leg and contralateral leg graft module. The system has anchor hooks for suprarenal fixation. The main device is delivered with an $18-21 \mathrm{~F}$ introducer system ipsilaterally and the contralaterally device is delivered with a $14-18 \mathrm{~F}$ introducer system. After the main part is opened, contralateral leg cannulation and extension is attached. Of note, this step may be time-consuming, according to the aneurysm anatomy.

\section{Anesthetic management}

Anesthetic management was chosen as local, loco-regional or general anesthesia (Table 1).

General anesthesia was induced using $3 \mathrm{mg} / \mathrm{kg}$ propofol, $1 \mu \mathrm{g} / \mathrm{kg}$ fentanyl, and $0.6 \mathrm{mg} / \mathrm{kg}$ rocuronium bromide. Anesthesia was maintained using 1 minimum alveolar concentration (MAC) sevoflurane in a $50 \%$ oxygen/air mixture and all patients received a bolus of remifentanil $1 \mu \mathrm{g} / \mathrm{kg}$ followed by an infusion of $0.5 \mu \mathrm{g} / \mathrm{kg} / \mathrm{min}$.

Prilocaine was used for local anesthesia in the groin, regardless of an additional intravenous sedation or pain therapy. Once the patient felt pain, additional doses were applied.

Locoregional anesthesia was performed uneventfully with $20 \mathrm{mg} 0.5 \%$ hyperbaric bupivacaine in the sitting position using 27 Gauge $(\mathrm{G})$ Quincke-type spinal needle at the L3-L4 interspace. Motor block up to T12 level was observed $15 \mathrm{~min}$ thereafter. A total dose of $0.05 \mathrm{mg} \cdot \mathrm{kg}^{-1}$ midazolam was used for mild intravenous sedation, while the patient was oxygenated by $2 \mathrm{~L} / \mathrm{min}$ nasal oxygen. Also, the following criteria were considered, while choosing the anesthesia type: ${ }^{[14]}$

1. For general anesthesia

- If the case is technically difficult and has the possibility for conversion to open repair

- If there will be intense femoral dissection for exposure

- Cases having a possibility to last long

- Not suitable for regional anesthesia due to coagulopathy

- Intolerable for the patient

\begin{tabular}{lccc} 
Table 1. Anesthesia types & & & \\
\hline & Total & Modular & Unibody \\
\hline Local/locoregional & 42 & 5 & 37 \\
General & 92 & 66 & 26 \\
\hline
\end{tabular}


2. For local anesthesia

- Shorter cases

- High-risk patients

- Not suitable for regional anesthesia due to coagulopathy

- Tolerable for the patient

3. For locoregional anesthesia

- The presence of relative comorbidity for general anesthesia (particularly respiratory diseases)

- Patients with cardiovascular comorbidity and if local anesthesia is not tolerable for the patient.

\section{Statistical analysis}

Statistical analysis was performed using the SPSS for Windows version 15.0 software (SPSS Inc., Chicago, IL, USA). Continuous variables with normal distribution were expressed in mean \pm standard deviation (SD), while categorical variables were expressed in number and frequency. Demographic features and perioperative variables were compared using the Mann-Whitney $U$ test and chi-square test. A $p$ value of $<0.05$ was considered statistically significant.

\section{RESULTS}

Baseline demographic and clinical characteristics of the patients are summarized in Table 2.

Of the patients, 42 were operated under locallocoregional anesthesia and 92 were operated under general anesthesia. None of the patients were needed to be converted to general anesthesia. The mean procedural time was $133.2 \pm 30.4 \mathrm{~min}$ in the locallocoregional group and $156.4 \pm 53.4 \mathrm{~min}$ in the general anesthesia group $(\mathrm{p}=0.01)$. The mean radioscopy time was $17.8 \pm 8.7 \mathrm{~min}$ in the local-locoregional group and $19.1 \pm 10.4 \mathrm{~min}$ in the general anesthesia group $(\mathrm{p}=0.619)$. The mean amount of radio-opaque solution was $62.9 \pm 12.5 \mathrm{~mL}$ in the local-locoregional group and $75.1 \pm 24.2 \mathrm{~mL}$ in the general anesthesia group, indicating a statistically significant difference between the groups $(\mathrm{p}=0.010)$.

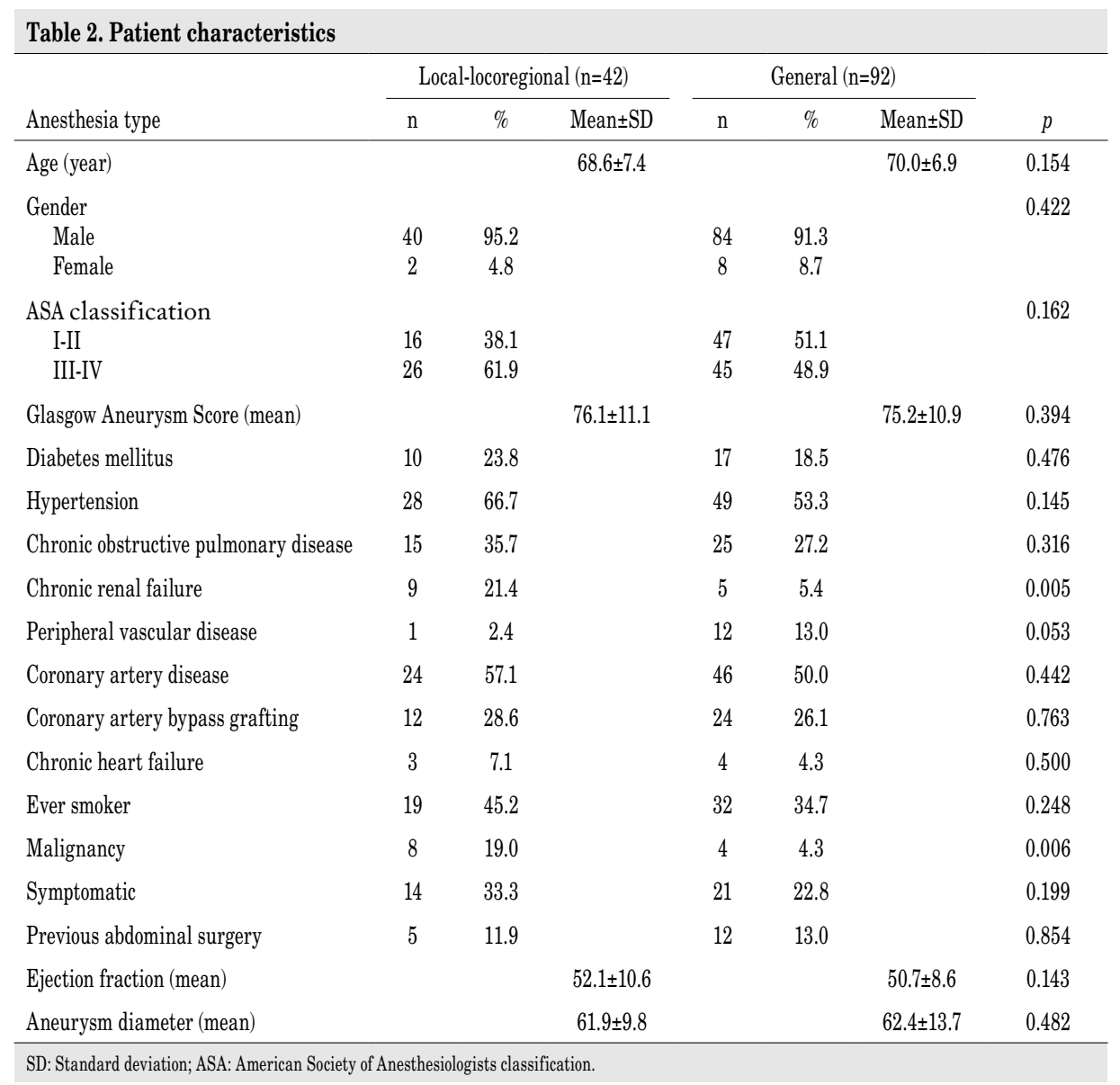


However, there were no statistically significant differences between the two groups in terms of the iliac or aortic extension requirement $(p=0.140$ and $\mathrm{p}=1.000$, respectively). In addition, balloon angioplasty $(\mathrm{p}=0.344)$, embolectomy $(\mathrm{p}=1.000)$, or graft interposition $(\mathrm{p}=1.000)$ requirement was not statistically significant, although the rate of endarterectomy necessity was higher in the locallocoregional group ( $\mathrm{p}=0.004)$.

In the postoperative period, there was one (1.1\%) early mortality in the general anesthesia group. Four patients (4.3\%) developed renal impairment. Of these patients, one died, the other needed hemodialysis, and the remaining two returned to normal renal functions. All these patients were at high risk for renal impairment with a serum creatinine level of $>1.8 \mathrm{mg} / \mathrm{dL}$. One patient $(1.1 \%)$ in the general anesthesia group had myocardial infarction after the procedure. In the local-locoregional group, the mean length of intensive care unit (ICU) stay was $8.5 \pm 6.4 \mathrm{~h}$ and the mean length of hospital stay (LOS) was $2.9 \pm 1.5$ days. In the general anesthesia group, the mean length of ICU stay was $9.6 \pm 0.4 \mathrm{~h}$ and the mean LOS was $3.1 \pm 2.9$ days, indicating a statistically significant difference between the groups in terms of the ICU stay $(\mathrm{p}=0.013)$.

\section{DISCUSSION}

After the first report with no death or significant morbidity associated with local anesthesia in 47 consecutive patients treated with EVAR, ${ }^{[11]}$ the benefits of anesthesia types were investigated. ${ }^{[10,11]}$ Although the Society of Vascular Surgery reported that using local anesthesia for EVAR had a lowlevel recommendation and low-level evidence, locallocoregional anesthesia seems to be the first choice among many surgeons for eligible patient. ${ }^{[7,8,15]}$ In addition, its feasibility, safety, and efficacy on reducing pulmonary complications and LOS have been proven. ${ }^{[8,16]}$

According to the specifications, endograft types have distinct advantages and disadvantages. Unibody grafts may be placed with one-side femoral artery exposure and there is no contralateral leg cannulation. These features make unibody endografts more compatible with local anesthesia. Occasionally, modular grafts are also suitable for local-locoregional anesthesia; however, if the patient has challenging anatomy or does not have suitable emotional status, the femoral cannulation site is deep or difficult to obtain. In such cases, we used general anesthesia in our study.
In the present study, the mean procedural time was significantly shorter in the local-locoregional group. The possible reason for this can be attributed to the fact that, in the local-locoregional group, unibody grafts were mostly used which does not require to be cannulated contralaterally and only ipsilateral femoral exposure is enough for the procedure. The amount of opaque solution is also less in the local-locoregional group. This can be explained with the placement of the bifurcation module of unibody grafts only under scopy without using the opaque solution.

Furthermore, the mean ICU stay was significantly shorter in the local-locoregional group, possibly due to the fact anesthetic recovery is longer with general anesthesia.

The ASA classification was another factor which affected our decision. For ASA III-IV high-risk patients, we gave much more effort to perform EVAR under local-locoregional anesthesia, due to a high number of cardiopulmonary comorbidities. However, if these patients were at high risk for conversion to open surgery, general anesthesia was chosen. Local anesthesia with appropriate sedation would be capable for an immobile patient during the procedure. Otherwise, there may be some measurement defects or lack of luxury for the medical team. Dijkstra et al. ${ }^{[17]}$ used general anesthesia for ASA III-IV highrisk patients; however, in our series, we used local anesthesia much more liberal. We preferred local anesthesia and sedation with the bispectral index at 60 to 85 . For sedation, before local anesthesia, we administered fentanyl $1 \mu \mathrm{g} / \mathrm{kg}, 1 \mathrm{mg}$ midazolam and, then, $0.05 \mu \mathrm{g} / \mathrm{kg} / \mathrm{min}$ remifentanil infusion. With these medications, we could configure effective and sufficient analgesia to block undesired patient motions, and patient discomfort due to pain. This also serves to hinder the undesirable side effects of general anesthesia over the cardiopulmonary system and the recovery period in ICU. Local anesthesia may give the surgical luxury of general anesthesia with the support of sedation. More liberal use of local anesthesia would highlight the non-invasive nature of endovascular procedures.

Local anesthesia first can be applied in $75 \%$ of patients undergoing EVAR procedure. Anesthetic conversion rates from local anesthesia to general anesthesia vary from 1 to $33 \%$ and seem to be lower in centers with more experience. ${ }^{[15,18]}$ In our series, there was no conversion and we achieved 100\% technical success. We believe that the accurate patient selection and patient characteristics, technical 
accomplishment, and successful collaboration between surgeons and anesthesia team were the key factors for successful early results, consistent with the literature. ${ }^{[19,20]}$

One of the major limitations of our study was that; it was compromised of a relatively small number of patients from a single center. Furthermore, the longterm data was not available for the current day. The short-term follow up may not be available enough to make such a definitive cocnlusion. Another remarkable limitation was the lack of some information regarding to the respective nature of the study. Some parameters such as visual pain analogue scale may be used for further studies.

In conclusion, type of anesthesia does not affect early postoperative results. Nevertheless, local anesthesia reduces ICU stay and shorter ICU stay is also important to reduce health-related cost, to increase the patient turnover rate in high volume centers, and to improve patient comfort. In addition, general anesthesia-related pulmonary complications can be avoided using local-locoregional anesthesia in eligible patients. Local anesthesia is more suitable and most commonly used in unibody grafts and high-risk patients.

\section{Declaration of conflicting interests}

The authors declared no conflicts of interest with respect to the authorship and/or publication of this article.

\section{Funding}

The authors received no financial support for the research and/or authorship of this article.

\section{REFERENCES}

1. Parodi JC, Palmaz JC, Barone HD. Transfemoral intraluminal graft implantation for abdominal aortic aneurysms. Ann Vasc Surg 1991;5:491-9.

2. EVAR trial participants. Endovascular aneurysm repair and outcome in patients unfit for open repair of abdominal aortic aneurysm (EVAR trial 2): randomised controlled trial. Lancet 2005;365:2187-92.

3. Brown LC, Thompson SG, Greenhalgh RM, Powell JT. Incidence of cardiovascular events and death after open or endovascular repair of abdominal aortic aneurysm in the randomized EVAR trial 1. Br J Surg 2011;98:935-42.

4. Zafer İşcan H, Utku Ünal E, Aytekin B, Cahit Sarıcaoğlu M, Karahasanoğlu O, Kiriş E, et al. Short-term results of endovascular intervention with bifurcation graft in elective infrarenal abdominal aortic aneurysm. Turk J Vasc Surg 2018;27:78-84.

5. İşcan HZ, Ünal EU, Sarıcaoğlu MC, Aytekin B, Soran Türkcan B, Akkaya B, et al. Elektif infrarenal abdominal aort anevrizmasına son beş yıldaki klinik yaklaşımımız: Erken dönem sonuçlar. Damar Cer Derg 2018;27:1-8

6. Dua A, Kuy S, Lee CJ, Upchurch GR Jr, Desai SS. Epidemiology of aortic aneurysm repair in the United States from 2000 to 2010. J Vasc Surg 2014;59:1512-7.

7. Armstrong RA, Squire YG, Rogers CA, Hinchliffe RJ, Mouton R. Type of anesthesia for endovascular abdominal aortic aneurysm repair. J Cardiothorac Vasc Anesth 2019;33:462-71.

8. Edwards MS, Andrews JS, Edwards AF, Ghanami RJ, Corriere MA, Goodney PP, et al. Results of endovascular aortic aneurysm repair with general, regional, and local/ monitored anesthesia care in the American College of Surgeons National Surgical Quality Improvement Program database. J Vasc Surg 2011;54:1273-82.

9. Aadahl P, Lundbom J, Hatlinghus S, Myhre HO. Regional anesthesia for endovascular treatment of abdominal aortic aneurysms. J Endovasc Surg 1997;4:56-61.

10. De Virgilio C, Romero L, Donayre C, Meek K, Lewis RJ, Lippmann M, et al. Endovascular abdominal aortic aneurysm repair with general versus local anesthesia: a comparison of cardiopulmonary morbidity and mortality rates. J Vasc Surg 2002;36:988-91.

11. Cao P, Zannetti S, Parlani G, Verzini F, Caporali S, Spaccatini A, et al. Epidural anesthesia reduces length of hospitalization after endoluminal abdominal aortic aneurysm repair. J Vasc Surg 1999;30:651-7.

12. Özyılmaz K, Yağan Ö, Taş N, Hancı V. Continuous spinal anaesthesia for endovascular repair of abdominal aortic aneurysm in high-risk patient. Turk J Anaesthesiol Reanim 2015;43:123-5.

13. Henretta JP, Hodgson KJ, Mattos MA, Karch LA, Hurlbert SN, Sternbach Y, et al. Feasibility of endovascular repair of abdominal aortic aneurysms with local anesthesia with intravenous sedation. J Vasc Surg 1999;29:793-8.

14. Kothandan H, Haw Chieh GL, Khan SA, Karthekeyan RB, Sharad SS. Anesthetic considerations for endovascular abdominal aortic aneurysm repair. Ann Card Anaesth 2016;19:132-41.

15. Chaikof EL, Dalman RL, Eskandari MK, Jackson BM, Lee WA, Mansour MA, et al. The Society for Vascular Surgery practice guidelines on the care of patients with an abdominal aortic aneurysm. J Vasc Surg 2018;67:2-77.

16. Geisbüsch P, Katzen BT, Machado R, Benenati JF, Pena $\mathrm{C}$, Tsoukas AI. Local anaesthesia for endovascular repair of infrarenal aortic aneurysms. Eur J Vasc Endovasc Surg 2011;42:467-73.

17. Dijkstra ML, van Sterkenburg SM, Lardenoye JW, Zeebregts CJ, Reijnen MM. One-Year Outcomes of Endovascular Aneurysm Repair in High-Risk Patients Using the Endurant Stent-Graft: Comparison of the ASA Classification and SVS/AAVS Medical Comorbidity Grading System for the Prediction of Mortality and Adverse Events. J Endovasc Ther 2016;23:574-82.

18. Karakişi SO, Ergene Ş, Hemşinli D, Küçüker ŞA. Our early and mid-term results for endovascular repair of abdominal aortic aneurysms. Turk Gogus Kalp Dama 2019;27:29-34. 
19. Yağan Ö, Özyılmaz K, Taş N, Hancı V. A retrospective analysis of comparison of general versus regional anaesthesia for endovascular repair of abdominal aortic aneurysm. Turk J Anaesthesiol Reanim 2015;43:35-40.
20. Aytekin B, Boğaçhan Akkaya B, Yılmaz M, Çetinkaya F, Salman N, Utku Ünal E, et al. Applicability of ASA classification system in elective endovascular aneurysm repair. Turk J Vasc Surg 2019;28:101-6. 